\title{
Progressive Collapse Analysis of Latticed Telecommunication Towers under Wind Loads
}

\author{
Shan Gao $\mathbb{D D}^{1,2}$ and Sheliang Wang ${ }^{2,3}$ \\ ${ }^{1}$ Postdoctoral Station of Civil Engineering, Chongqing University, Chongqing 400030, China \\ ${ }^{2}$ Shaanxi Key Laboratory of Safety and Durability of Concrete Structures, Xijing University, Xi'an 710123, China \\ ${ }^{3}$ School of Civil Engineering, Xi'an University of Architecture and Technology, Xi'an 710123, China \\ Correspondence should be addressed to Shan Gao; gaoshan@hit.edu.cn
}

Received 22 August 2017; Revised 24 October 2017; Accepted 1 November 2017; Published 24 January 2018

Academic Editor: John Mander

Copyright (c) 2018 Shan Gao and Sheliang Wang. This is an open access article distributed under the Creative Commons Attribution License, which permits unrestricted use, distribution, and reproduction in any medium, provided the original work is properly cited.

As the antenna-supporting structures, latticed telecommunication steel towers are considered as critical members of telecommunication infrastructures. It is necessary to perform progressive collapse analysis of lattice telecommunication towers under wind loads. The present study conducts a nonlinear dynamic analysis on $50 \mathrm{~m}$ high typical standard latticed telecommunication tripole tower and angle tower by alternative load path method. The finite element models for two towers subjected to design wind loads are developed by ABAQUS. The analysis results show that, for $50 \mathrm{~m}$ high standard tripole tower, the member failure in the first three tower sections from tower top would not trigger the collapse of the tower. From the fourth tower section to tower bottom, the member failure at certain wind direction may cause a collapse. For $50 \mathrm{~m}$ high standard angle tower, the single member failure in any tower section would not cause the collapse of the tower. A dynamic sensitivity index is proposed to identify the most unfavorable wind direction for tripole tower and angle tower. A progressive collapse fragile curve based on collapse probability of telecommunication tower under wind loads is proposed to assess the anticollapse performance of the towers.

\section{Introduction}

Progressive collapse is a chain failure that propagated vertically or horizontally in structures which is caused by a local structural damage under additional loads. Due to the unpredictability of additional loads, the anticollapse design is not quantitatively considered in the structural design until the notorious terrorist attack on the World Trade Center. In order to protect the important buildings from terrorist attacks or other additional loads, a series of standards and codes are issued to assess and diminish the potential of progressive collapse in structures [1-3].

The continuing growth of communities requires the expansion of telecommunication networks. Reliable and noninterruptible telecommunication signals are crucial, especially under the natural disaster or terrorist attack. As the antenna-supporting structures, latticed steel towers are considered as a lifeline project in telecommunication engineering. A good assessment for the structural response of latticed telecommunication towers under additional loads is essential for the safety of telecommunication engineering.

Due to the numerous amount and construction repeatability of telecommunication towers, the potential danger and flaws in the design tend to be neglected by designers and engineers. Telecommunication towers operate in outdoor natural environment for a long period, in which case the work condition varies greatly and the accidental loads are hard to predict. The safety of the telecommunication towers is threatened by many factors, such as extreme weather or vandalism. Based on the geological and climatic conditions, additional considerations are required in the design of telecommunication towers $[4,5]$. The antennasupporting towers normally involve guyed masts, monopole towers, and latticed towers. The collapse of guyed mast and monopole towers is mostly due to the rupture of guys or overall overturning. The reasons for the collapse of latticed towers are more complicated. It is necessary to perform progressive collapse analysis of lattice telecommunication towers under design loads and accidental loads. 
Alternative path method (APM) is widely adopted in the anticollapse design and analysis of structures, especially frame structures. This methodology involves the identification of key structural elements and the assessment on remainder of the structure after element removal. According to the importance of the structure, linear static analysis, nonlinear static analysis, linear dynamic analysis, and nonlinear dynamic analysis are adopted to perform the assessment for the potential to progressive collapse. Nonlinear dynamic analysis is the most practical method whilst linear static analysis is the easiest to implement. A dynamic increase factor (DIF) is commonly used in linear static analysis to make the assessment more realistic. The susceptibility and redundancy analysis of progressive collapse in structures are also based on APM. By introducing the susceptibility or redundancy index, the key structural members could be identified by APM.

Several studies have been performed on the progressive collapse of structures through APM. Powell compared the results obtained by different analysis procedures and concluded that using dynamic increase factor of 2.0 in linear static analysis may be conservative [6]. In addition, the research conducted by Ruth et al. also showed that the value of 1.5 was suitable for linear static analysis of steel frame structures considering dynamic effect [7]. Kim and Kim performed APM on steel frame structures whose results showed that nonlinear dynamic analysis would result in larger responses in structures than static analysis [8]. Fu developed a 3-D model for steel frame with concrete slab. The results of the research based on this model showed that the removal of the column at a low elevation was more likely to trigger progressive collapse than that of the column at a high elevation [9]. Khandelwal and El-Tawil investigated the robustness of structures by using "pushdown analysis." The results showed that the dynamic increase factor of 2.0 was significantly higher than the actual value in the study [10]. Song et al. developed both $2-\mathrm{D}$ and 3-D models for steel frame structures. The results of progressive collapse analysis indicated that 3-D finite element model was more accurate than 2-D finite element model in presenting the behavior of the structure in the scenario of column loss [11]. El Kamari et al. simulated the failure of Roissy Charles de Gaulle Airport and pointed out that the defective construction and irrational design in the project resulted in the collapse [12]. Gerasimidis and Sideri proposed a new partial-distributed damage method for steel moment frames. The results showed that local failure in the system can remarkably change the collapse response of the structure [13]. Asgarian et al. conducted a progressive collapse analysis of a lattice transmission tower by using APM. A capacity-to-demand ratio was proposed to identify the key elements. The study also showed that power transmission towers may avoid from progressive collapse under single element damage, due to the adequate alternative load paths [14].

The study in this paper aims at assessing the sensitivity of typical latticed telecommunication towers to progressive collapse. ABAQUS [15] is implemented to develop finite element (FE) model for the towers. The latticed towers are

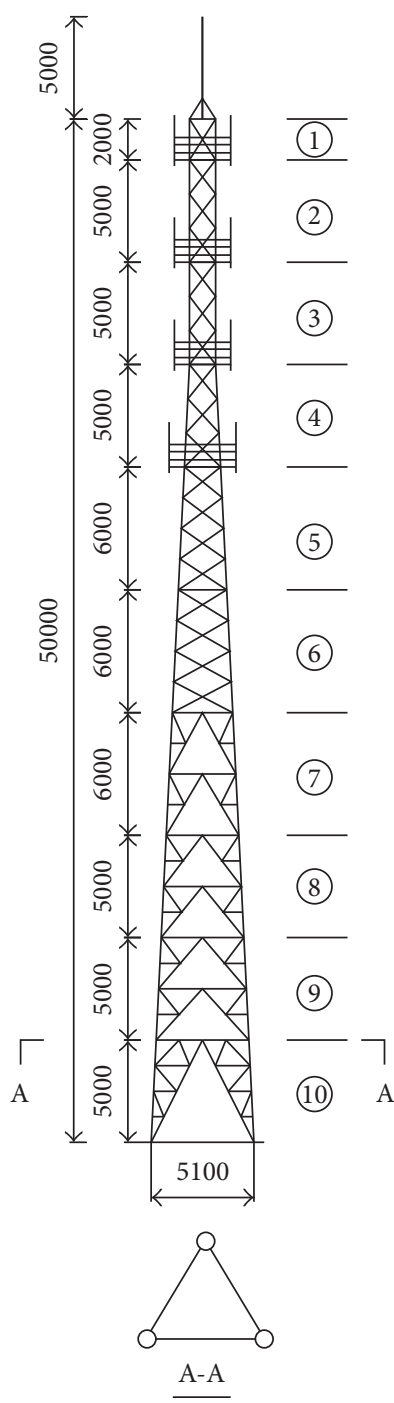

(a)

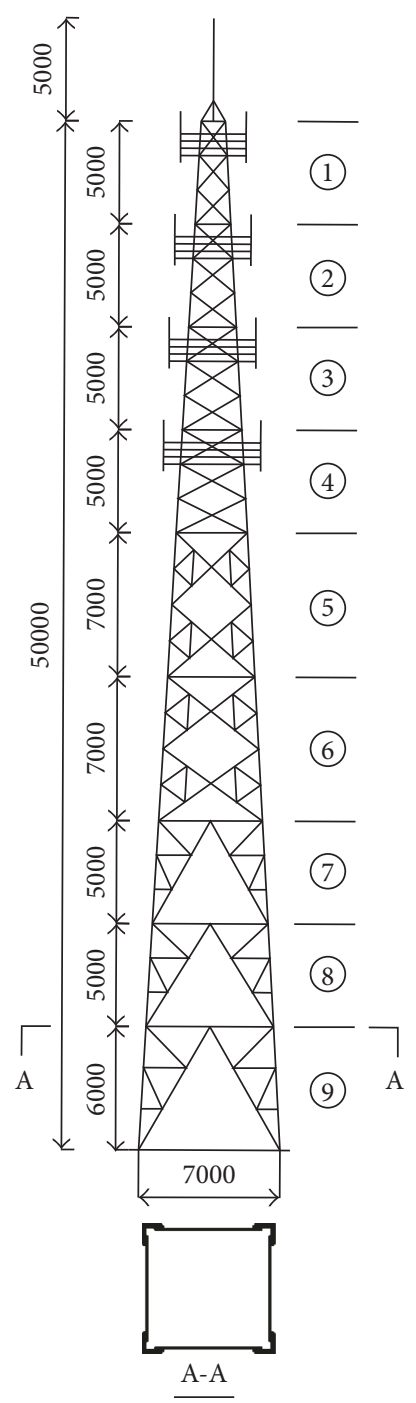

(b)
Figure 1: Geometry of the prototype towers (mm). (a) Tripole tower; (b) angle tower.

subjected to design wind loads. Nonlinear dynamic analysis is conducted on typical standard tripole tower and angle tower by alternative load path method. A dynamic sensitivity index and a collapse probability are both proposed to evaluate the potential to progressive collapse of latticed telecommunication tower.

\section{Development and Validation of FE Model}

2.1. Prototype Structures. Unlike the design of building structures, the design of telecommunication towers which is labor-intensive shows the characteristic of repeatability and similarity. In order to improve design efficiency, the Chinese government issues a set of standard design drawings for telecommunication towers, namely, "Drawing Collection of Telecommunication Steel Tower (DCTST)" in the year of 2014 [16]. From then on, all new telecommunication steel towers in China are built referring to DCTST, except in special cases. 
TABLE 1: Member sections of tripole tower ( $\mathrm{mm})$.

\begin{tabular}{lcccccccccc}
\hline Tower section number & 1 & 2 & 3 & 4 & 5 & 6 & 7 & 8 & 9 & 10 \\
\hline Leg member section & $\Phi 89^{*} 5$ & $\Phi 114^{*} 5$ & $\Phi 146^{*} 6$ & $\Phi 159^{*} 8$ & $\Phi 180^{*} 10$ & $\Phi 194^{*} 10$ & $\Phi 219^{*} 10$ & $\Phi 219^{*} 12$ & $\Phi 219^{*} 12$ & $\Phi 219^{*} 12$ \\
Cross-brace member section & L50*5 & L63*5 & L70*5 & L70*5 & L70*5 & L70*5 & L80*6 & L80*6 & L80*6 & L80*6 \\
\hline
\end{tabular}

TABle 2: Member sections of angle tower ( $\mathrm{mm})$.

\begin{tabular}{|c|c|c|c|c|c|c|c|c|c|}
\hline Tower section number & 1 & 2 & 3 & 4 & 5 & 6 & 7 & 8 & 9 \\
\hline Leg member section & $\mathrm{L}^{2} 80^{*} 6$ & $\mathrm{~L} 100^{*} 8$ & $\mathrm{~L} 125^{*} 10$ & $\mathrm{~L} 140^{*} 12$ & L160*14 & L180*16 & $\mathrm{L} 180^{*} 16$ & L $200^{*} 16$ & $\mathrm{~L} 200^{*} 18$ \\
\hline Cross-brace member section & $\mathrm{L}^{6} 3^{*} 5$ & $\mathrm{~L} 63 * 5$ & $\mathrm{~L} 63 * 5$ & $\mathrm{~L} 70 * 5$ & $\mathrm{~L} 75^{*} 6$ & $\mathrm{~L} 80^{*} 6$ & L90*7 & L90*7 & $\mathrm{L} 100^{*} 7$ \\
\hline
\end{tabular}

A standard tripole tower and a standard angle tower from DCTST are chosen as prototype structures. The total height of two towers is $55 \mathrm{~m}$ including a $5 \mathrm{~m}$ height lightning rod. The general configuration of the towers is shown in Figure 1. The right column of numbers in the figures shows the number of each tower section. Tripole tower consists of three pole-legs whilst angle tower consists of four angle-legs. Four platforms are installed on both towers. Each platform carries six sets of antennas. Member sections of the towers are listed in Tables 1 and 2. Chinese grade Q345 structural steel is used for all steel members.

2.2. Development of FE Model. Two 3-D nonlinear FE models of the prototype towers are developed by using ABAQUS as shown in Figure 2. Antennas, platforms, and other accessories are all included in the models. ${ }^{*}$ Truss elements (T3D2) and *Beam elements (B31) from ABAQUS library are adopted to simulate cross-brace members and leg members. Antennas, platforms, and other accessories are modeled by * solid elements (C3D8R). Ends of the cross braces with two bolts are assumed to be pin connections. Steel stress-strain relationship is as shown in Figure 2(c). Elastic modulus of $206 \mathrm{GPa}$, yield stress of $345 \mathrm{MPa}$, and strain hardening of $1 \%$ are assigned for the material properties of steel. Four-leg feet of the model are fixed on the ground.

2.3. Validation of FE Model. In order to validate the finite element models in Figure 2, modal analysis is conducted by ABAQUS and SAP2000 at the same time. The comparison of natural vibration frequencies is shown in Table 3. It can be seen that the difference between the results of the first five modes is within $1 \%$ which proves the accuracy of the models.

\section{Finite Element Modeling Technique}

3.1. Loads. Gravity loads at the model are considered by assigning density to structural members, antennas, platforms, and other accessories. Horizontal wind loads are calculated by (1) according to the Chinese Load code for the design of building structures [17]:

$$
w_{k}=\beta_{z} \mu_{s} \mu_{z} w_{0} \text {, }
$$

where $w_{0}$ stands for the reference wind pressure; $\beta_{z}$ for the gust effect factor; $\mu_{s}$ for the topographic factor; and $\mu_{z}$ for the velocity pressure coefficient.

The reference wind pressure $w_{0}$ for two towers in this study, namely, the design wind pressure in DCTST, is $0.65 \mathrm{kN} / \mathrm{m}^{2}$. The wind loads as shown in Table 4 are applied as concentrated forces at the top of each tower section. The additional values in Table 4 are the wind loads sustained by the platform. There loads are applied to the tower section by which the platform is supported. Based on the appearance of the chosen towers, wind directions are selected for two towers as shown in Figure 3. The applied wind loads in the façade view is shown in Figure 3(c).

The gravity loads of antennas, platform, and other accessories on each platform are as shown in Table 5 according to DCTST. Live loads on platform are adopted as $1.0 \mathrm{kN} / \mathrm{m}$. The vertical load combination on platform is used in the analysis as follows:

$$
\text { Load }=\mathrm{DL}+0.25 \mathrm{LL}
$$

where DL and LL stand for gravity loads and live loads, respectively.

3.2. Alternative Path Method. A nonlinear dynamic analysis based on alternative path method is conducted by three steps as follows: (a) Horizontal wind loads are applied at the model in a static analysis step; (b) the structural member is removed over a predefined period in a dynamic analysis step; and (c) the dynamic response of the remaining model is monitored until the model is stabilized in a dynamic analysis step.

According to GSA guideline, a failure period which is no more than $1 / 10$ of the period associated with the structural response mode is recommended in the member removal step. According to the natural vibration frequencies in Table 3, $0.07 \mathrm{~s}$ and $0.05 \mathrm{~s}$ of failure period are adopted for tripole tower and angle tower, respectively.

In dynamic analysis, Rayleigh damping is employed to create the damping matrix of the model. The typical Rayleigh damping matrix is as follows:

$$
C=\alpha M+\beta K,
$$




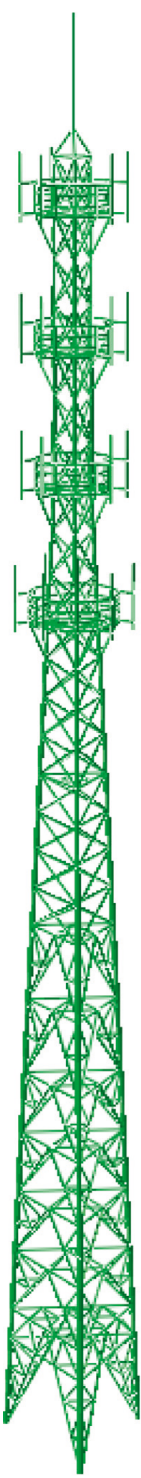

(a)

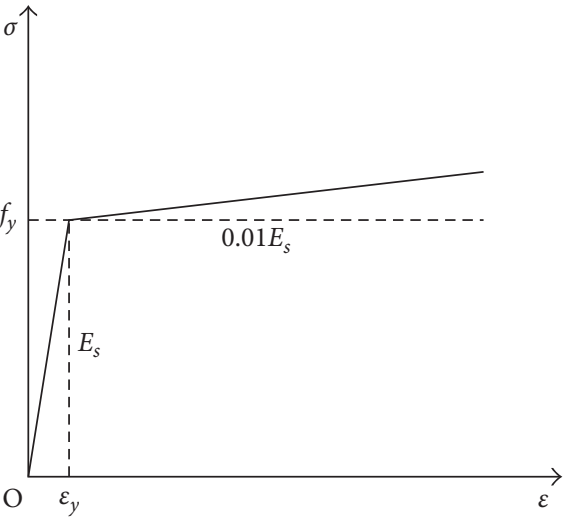

(c)

Figure 2: Finite element model. (a) Tripole tower; (b) angle tower; (c) steel stress-strain relationship.

where $M$ and $K$ stand for mass matrix and stiffness matrix of the structure, respectively, and $\alpha$ and $\beta$ stand for the mass damping coefficient and the stiffness damping coefficient, respectively.
The coefficient $\alpha$ and $\beta$ which are derived from (4) are introduced into ABAQUS to determine the damping matrix of the model.

$$
\begin{aligned}
& \alpha=\xi \frac{2 \omega_{1} \omega_{2}}{\omega_{1}+\omega_{2}} \\
& \beta=\xi \frac{2}{\omega_{1}+\omega_{2}},
\end{aligned}
$$

where $\omega_{1}$ and $\omega_{2}$ stand for the first-order and second-order natural vibration frequency, respectively, and $\xi$ for the damping ratio which is 0.02 for steel structures.

3.3. Defined Failure Scenarios. Three pole-legs in tripole tower are numbered as shown in Figure 4(a). For wind direction Tri-A and Tri-B, the failure of leg members in poleleg 1 is most unfavorable. For wind direction Tri-C, the failure of leg members in pole-leg 2 and 3 are both analyzed. From elevation view, the bottom leg member of each tower section is removed notionally as shown in Figure 4(b), namely, ten failure scenarios for each pole-leg.

Figure 5(a) shows the number of angle-legs and the corresponding wind direction. For wind direction Ang-A, angle-leg 1 and 2 are chosen to analyze due to the symmetrical arrangement. Angle-leg 1 and 3 would be considered in the analysis for wind direction Ang-B. Nine failure scenarios are defined for each angle-leg as shown in Figure 5(b).

\section{Results and Discussions}

4.1. Tripole Tower. The horizontal displacement-time history curves of tower top whose elevation is $50 \mathrm{~m}$ are recorded to present the dynamic response of the tower under leg member removal in a certain tower section. According to [18], the horizontal displacement limitation for tower top in nonlinear analysis is $1 / 50$ of the elevation. In this study, this limitation is $1 \mathrm{~m}$ for both tripole tower and angle tower.

4.1.1. Wind Direction Tri-A. Pole-leg 1 is in compression at wind direction Tri-A. Figure 6 shows the horizontal displacement-time history curves of tower top under leg member removal in pole-leg 1 at wind direction Tri-A. As Figure 6 shows, the horizontal displacement of tower top is $0.353 \mathrm{~m}$ after the horizontal wind loads are applied which is smaller than the limitation. For the first three tower sections, the horizontal displacement of tower top is smaller than $1 \mathrm{~m}$ after the leg member removed which means the tower does not collapse in these three failure scenarios. After the leg member is removed in tower section 4 , the horizontal displacement of tower top spikes from $0.353 \mathrm{~m}$ to $2 \mathrm{~m}$ which is two times larger than the limitation; even then, the tower does not collapse. It suggests that the failure of the leg members in tower section 4 may have the potential to trigger the collapse of the tower. For the failure scenarios of leg members in the rest of the tower sections, the horizontal displacement of tower top tends to infinity which means that the tower would collapse. 
TABle 3: Comparison of natural vibration frequencies.

\begin{tabular}{lllccccc}
\hline & & Mode & 1 & 2 & 3 & 4 & 5 \\
\hline \multirow{2}{*}{ Tripole tower } & \multirow{2}{*}{ Frequency $(\mathrm{Hz})$} & ABAQUS & 1.3010 & 1.3011 & 2.6352 & 2.6354 & 3.2713 \\
& & SAP2000 & 1.3155 & 1.3165 & 2.7095 & 2.7098 & 3.1850 \\
\multirow{3}{*}{ Angle tower } & \multirow{2}{*}{ Frequency $(\mathrm{Hz})$} & ABAQUS & 2.2200 & 2.2226 & 2.5869 & 2.5873 & 5.7509 \\
& & SAP2000 & 2.2647 & 2.2649 & 2.6095 & 2.6098 & 6.8850 \\
\hline
\end{tabular}

TABLE 4: Wind loads $(\mathrm{kN})$.

\begin{tabular}{lcccccccccc}
\hline & 1 & 2 & 3 & 4 & 5 & 6 & 7 & 8 & 9 & 10 \\
\hline Tripole tower & 6.8 & $9.5+12$ & $9.3+10.5$ & $8.9+9.0$ & $10.9+7.7$ & 10.7 & 10.2 & 8.0 & 6.8 & 6.8 \\
Angle tower & $9.4+18$ & $11.5+15.5$ & $11.3+13.5$ & $12.7+11.5$ & 18.8 & 12.8 & 9.4 & 9.3 & 9.1 & - \\
\hline
\end{tabular}

4.1.2. Wind Direction Tri-B. Pole-leg 1 is in tension at wind direction Tri-B. Figure 7 shows the horizontal displacementtime history curves of tower top under leg member removal in pole-leg 1 at wind direction Tri-B. It can be seen that the failure of leg members in the first three tower sections does not cause the collapse of the tower. The failure of leg members in tower section 4 and tower section 5 would remarkably increase the horizontal displacement of tower top, yet not directly cause the collapse of the tower. For the failure scenarios in other lower tower sections, the collapse of the tower is observed. It is worth noticing that the horizontal displacement of tower top in the failure scenarios of first four tower sections is smaller than that at wind direction Tri-A. It is because the gravity load of the tower would bring about internal force in the same direction with wind loads at wind direction Tri-A. On the contrary, the gravity load of the tower would contribute to resist the collapse at wind direction Tri-B. It may be concluded that tripole tower possesses better anticollapse resistance at wind direction Tri-B than that wind direction Tri-A.

4.1.3. Wind Direction Tri-C. At wind direction Tri-C, poleleg 2 is in compression whilst pole-leg 3 is in tension. The horizontal displacements of tower top at both down wind direction and vertical wind direction are monitored due to the torsional deformation of the tower at wind direction Tri-C.

Figure 8 shows the horizontal displacement-time history curves of tower top under leg member removal in pole-leg 2 at wind direction Tri-C. It can be seen that the failure of leg members in the pole-leg 2 of the first three tower sections does not cause the collapse of the tower. The vector sum of horizontal displacement of tower top in the failure scenario of tower section 4 is about $1.14 \mathrm{~m}$ which is a little larger than the limitation. It may be concluded that the failure scenario of tower section 4 may not initiate the collapse of the tower. The failure in the rest of the tower sections would trigger the collapse of the tower, due to the nonconvergence of horizontal displacement of tower top.

Figure 9 shows the horizontal displacement-time history curves of tower top under leg member removal in pole-leg 3 at wind direction Tri-C. Comparing with pole-leg 2, the horizontal displacement of tower top in each scenario of pole-leg 3 is smaller due to the beneficial effect of gravity loads. Based on the above analysis of three wind directions, it may be concluded that the member failure of the pole-leg in compression is more unfavorable than that in tension.

\subsection{Angle Tower}

4.2.1. Wind Direction Ang-A. At wind direction Ang-A, angle-leg 1 is in tension whilst angle-leg 2 is in compression. The horizontal displacements of tower top at both down wind direction and vertical wind direction are recorded due to the torsional deformation of angle tower at wind direction Ang-A.

Figures 10 and 11 show the horizontal displacement-time history curves of tower top at wind direction Ang-A under leg member removal in angle-leg 1 and angle-leg 2, respectively. As they show, the horizontal displacement of tower top is $0.114 \mathrm{~m}$ after the horizontal wind loads are applied which is only 0.1 times of the limitation. Meanwhile, it is worth noticing that the failure of leg members in angle-leg 1 and angle-leg 2 would not trigger the collapse of angle tower. After vibrating, the horizontal displacement of tower top remains under the displacement limitation. The results show that angle tower possesses the redundancy and resistance to progressive collapse under the scenario of single member failure at wind direction Ang-A.

4.2.2. Wind Direction Ang-B. At wind direction Ang-A, angle-leg 1 is in tension whilst angle-leg 3 is in compression. Figures 12 and 13 show the horizontal displacement-time history curves of tower top at wind direction Ang-B under leg member removal in angle-leg 1 and angle-leg 3, respectively. It can be seen that the maximum horizontal displacement of tower top in the failure scenarios is about $0.325 \mathrm{~m}$ which is much smaller than the limitation. This shows that angle tower is also insensitive to progressive collapse under the scenario of single member failure at wind direction Ang-B.

It is worth noticing that the horizontal displacement of tower top at wind direction Ang-B is larger than that at wind direction Ang-A. It is because only angle-leg 1 and angle-leg 3 are bearing the wind load at wind direction Ang-B whilst four angle-legs are all sustaining the wind load at wind direction Ang-A. It means that more internal force needs to be redistributed under the member failure at wind direction Ang-B than that at wind direction Ang-A. 


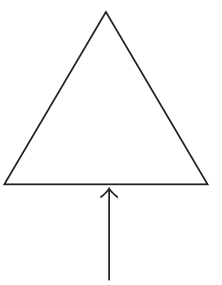

Tri-A $\left(+90^{\circ}\right)$

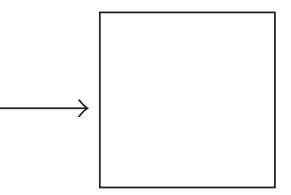

Ang-A $\left(+90^{\circ}\right)$

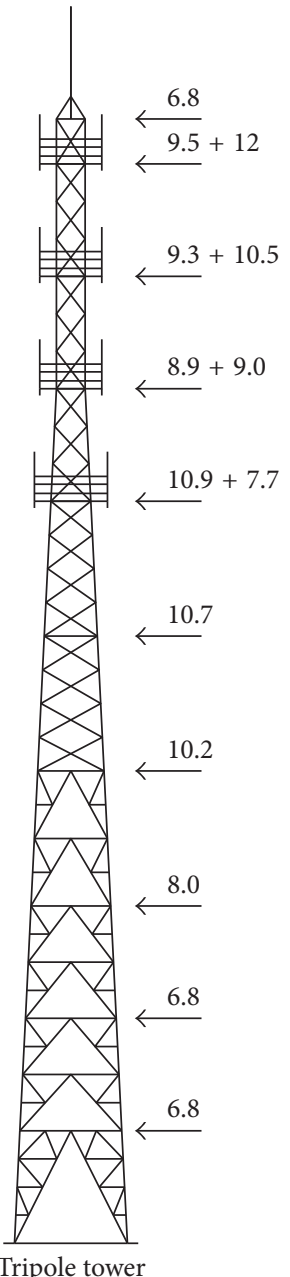

Tripole tower

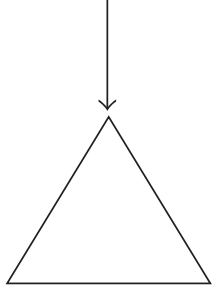

Tri-B $\left(-90^{\circ}\right)$

(a)

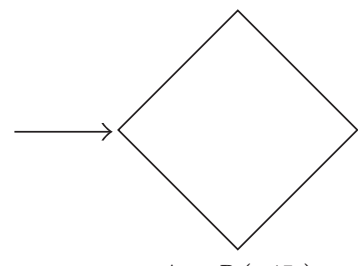

Ang-B $\left(+45^{\circ}\right)$

(b)

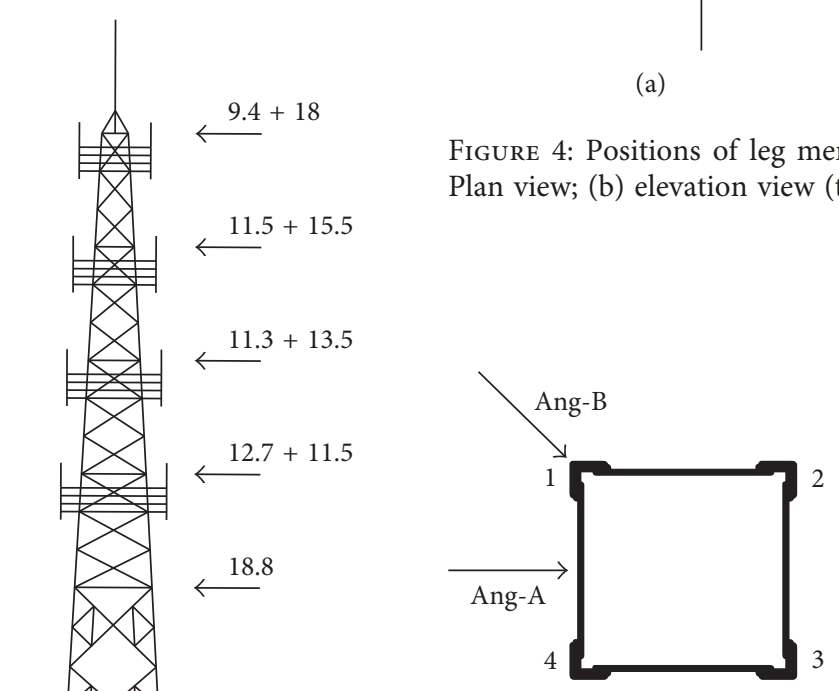

(a)

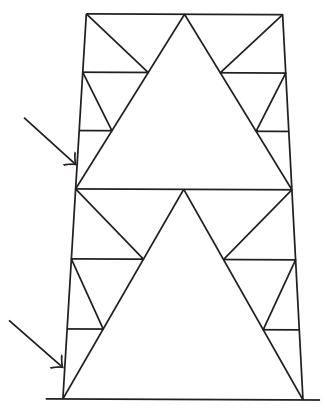

(b)
Figure 5: Positions of leg member removal at angle tower. (a) Plan view; (b) elevation view (take section 9 and 10 for example).

limitation value $\mathrm{DSI}_{\lim }$ is 1.83 and 7.77 for tripole tower and angle tower, respectively. If the DSI of certain member is larger than $\mathrm{DSI}_{\text {lim }}$, the member has potential to trigger the collapse of the tower. DSI lim could be specified based on the different limitation in standards and codes.

$$
\text { DSI }=\frac{D_{\mathrm{md}}-D_{\text {is }}}{D_{\text {is }}},
$$

where $D_{\mathrm{md}}$ stands for the maximum dynamic displacement and $D_{\text {is }}$ for the initial static displacement.

Figure 14 shows the DSIs of tripole tower and angle tower. As shown in Figure 14(a), the first three tower sections are safe in all three wind directions. The absence of DSI from tower section 6 to tower section 10 in Figure 14(a) implies the collapse of the tower. The DSI of pole-leg 2 in tower section 4 and poleleg 3 in tower section 5 at wind direction Tri-C is only 1.1 times higher than the limitation value $\mathrm{DSI}_{\mathrm{lim}}$. Comparing the DSIs of different wind directions, it could be concluded that wind
4.3. Dynamic Sensitivity Index. Dynamic sensitivity index (DSI) as described by (5) is used in the design to assess the structural members in tower legs. Based on the horizontal displacement limitation which is $1 \mathrm{~m} \mathrm{[18],} \mathrm{the} \mathrm{corresponding}$

\begin{tabular}{lcccc}
\hline From top & 1st & 2nd & 3rd & 4 th \\
\hline Tripole tower & 32 & 32 & 32 & 40 \\
Angle tower & 36 & 40 & 50 & 66 \\
\hline
\end{tabular}

Figure 3: Wind directions. (a) Tripole tower; (b) angle tower; (c) façade view $(\mathrm{kN})$. 


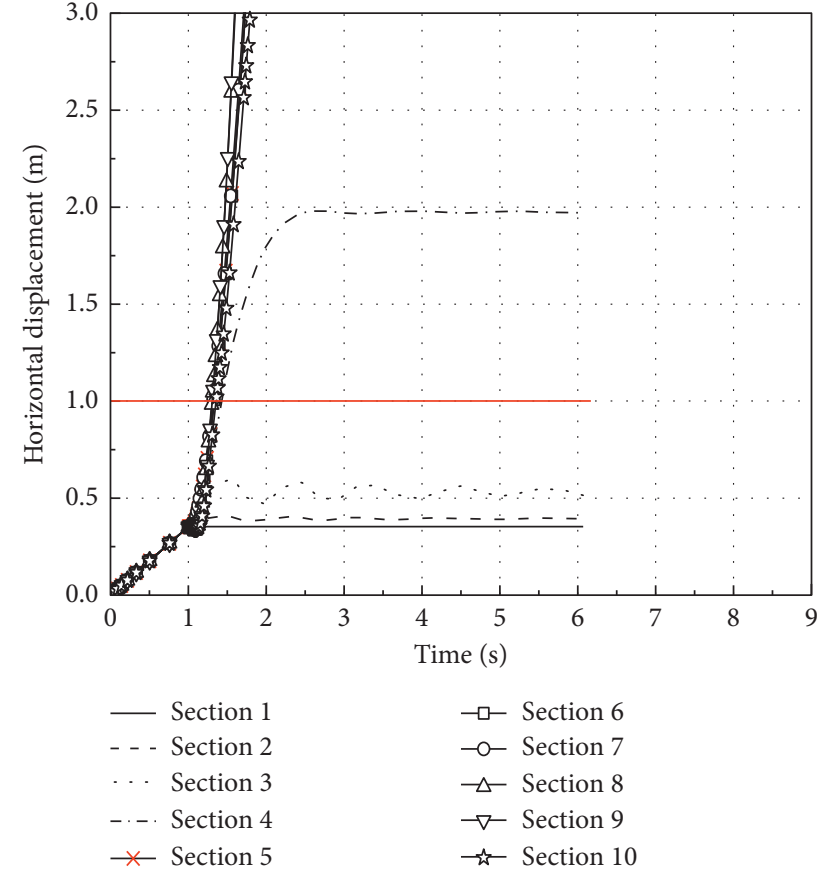

Figure 6: Leg member removal in pole-leg 1 at wind direction Tri-A.

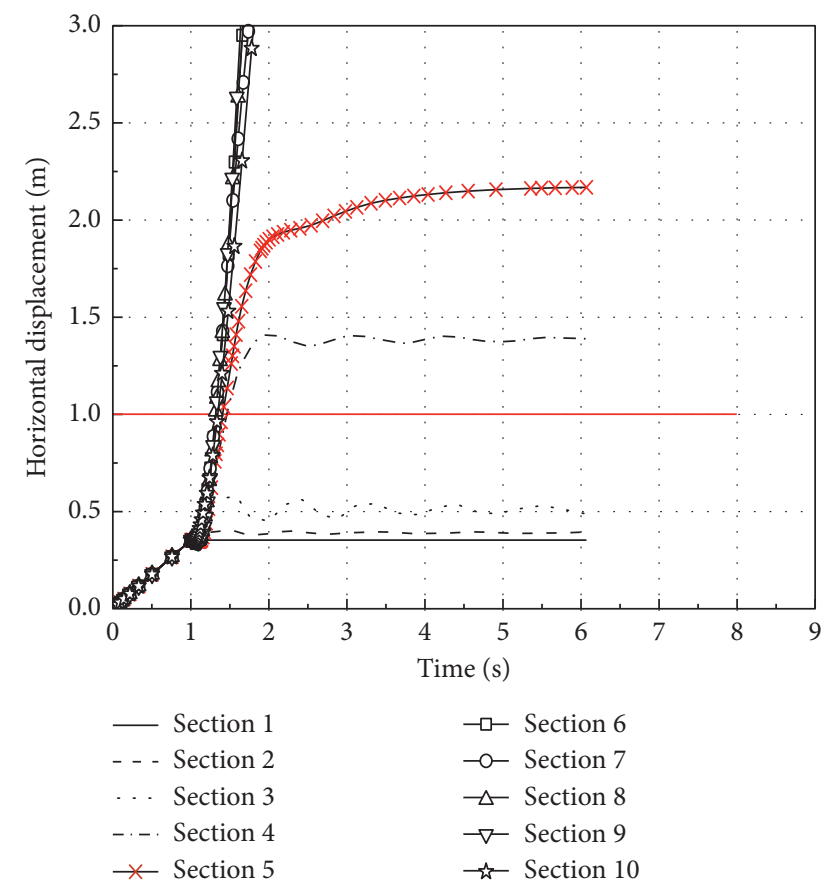

Figure 7: Leg member removal in pole-leg 1 at wind direction Tri-B.

direction Tri-A that causes single pole-leg in compression is the most unfavorable wind direction for tripole tower. As shown in Figure 14(b), the DSIs of angle tower are much lower than the limitation value which suggests that there is no potential to collapse in angle tower under the scenario of single angle-leg failure. Still, it can be seen in Figure 14(b) that wind direction Ang-B is the most unfavorable wind direction for angle tower.

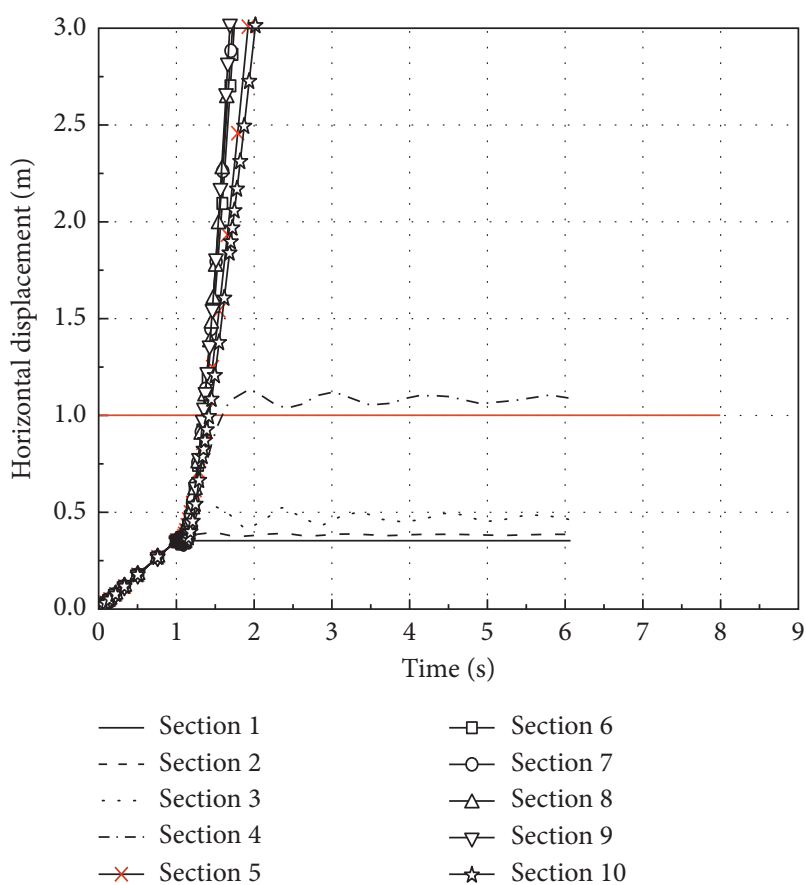

(a)

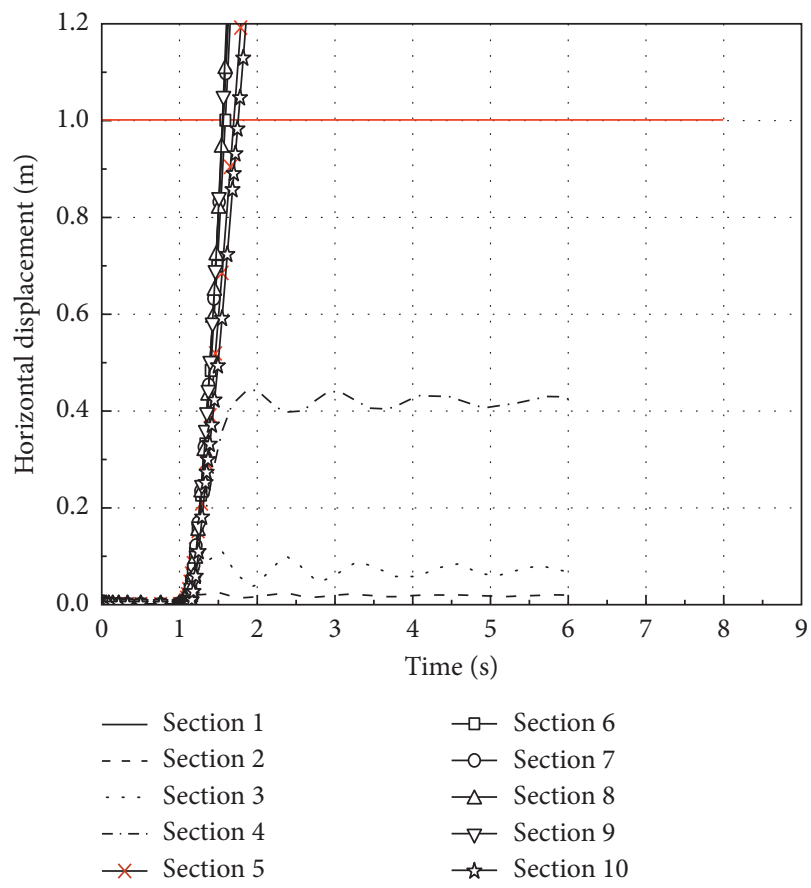

(b)

Figure 8: Leg member removal in pole-leg 2 at wind direction Tri-C. (a) Down wind direction; (b) vertical wind direction.

4.4. Collapse Probability. Based on the research in [19], the collapse probability of telecommunication tower under wind loads $P[C]$ can be expressed as

$$
P[C]=P\left[\frac{C}{L W}\right] \cdot P[L] \cdot P[W],
$$




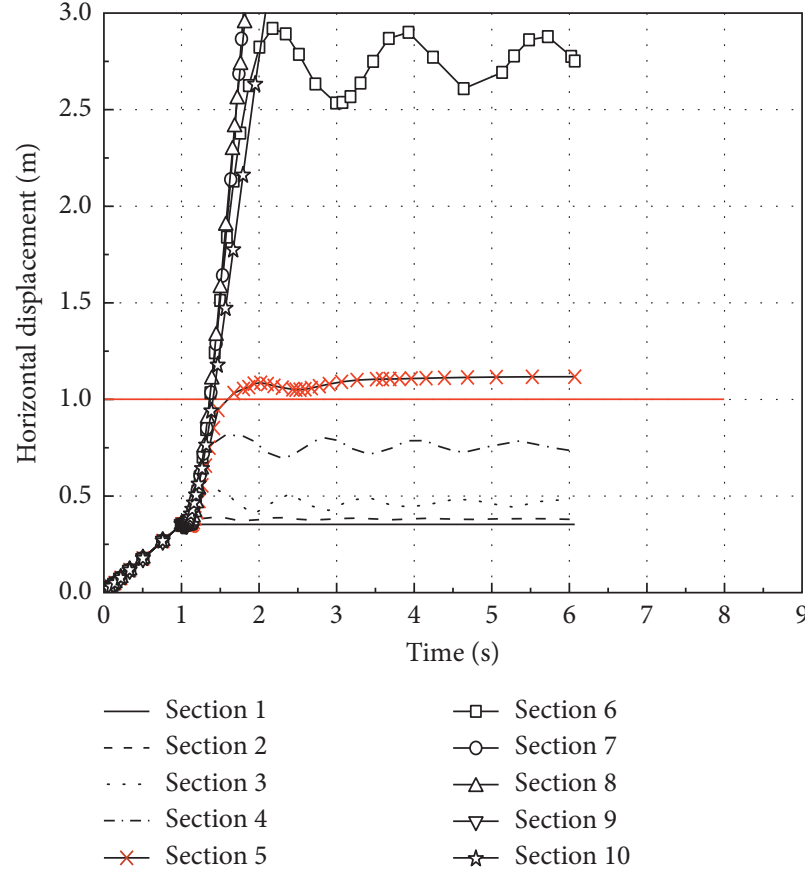

(a)

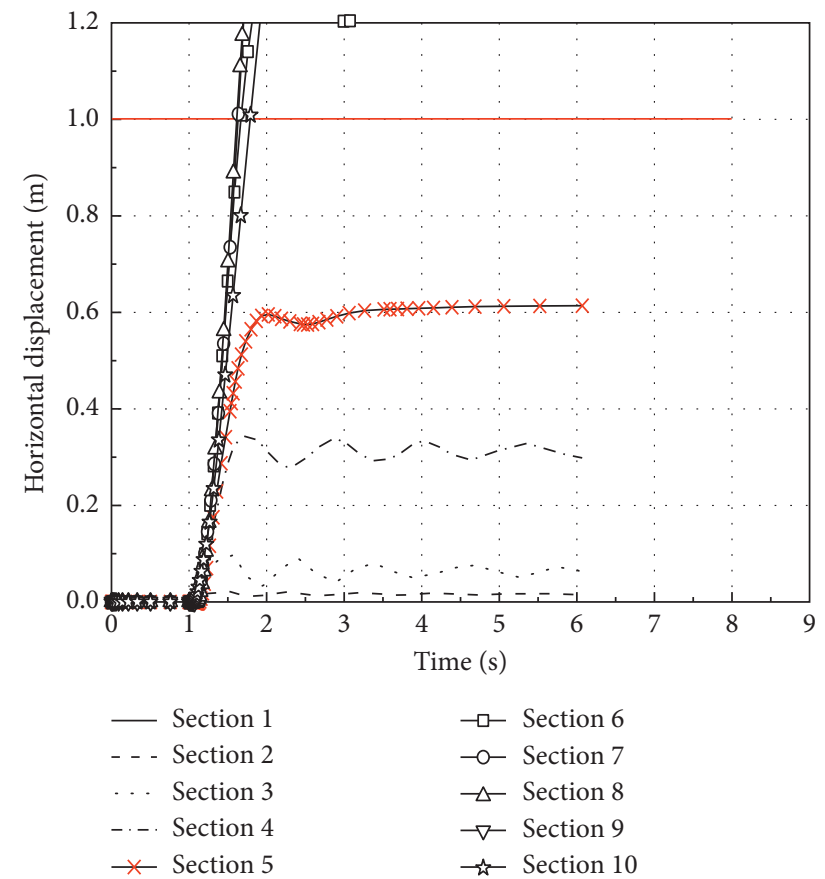

(b)

Figure 9: Leg member removal in pole-leg 3 at wind direction Tri-C. (a) Down wind direction; (b) vertical wind direction.

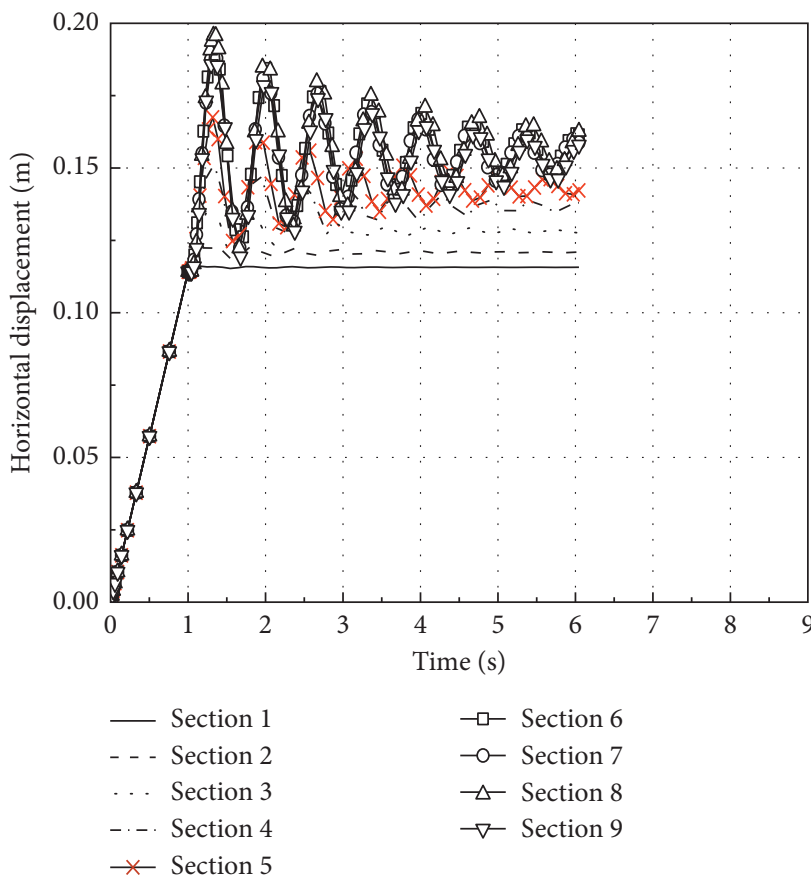

(a)

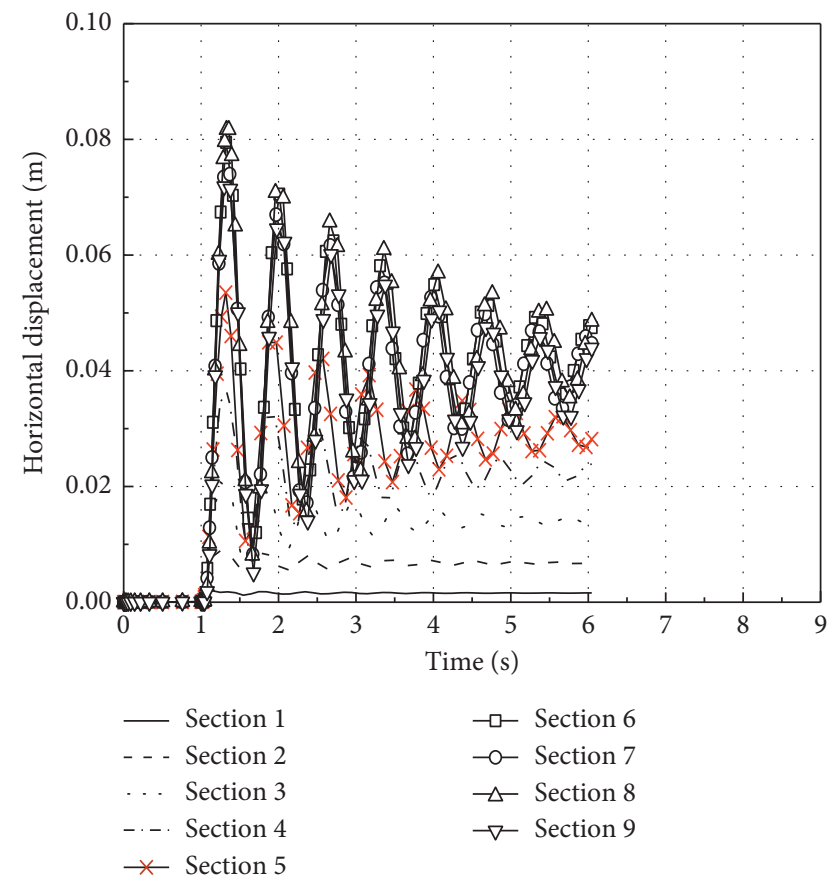

(b)

FIGURE 10: Leg member removal in angle-leg 1 at wind direction Ang-A. (a) Down wind direction; (b) vertical wind direction.

where $P[W]$ is the probability of most unfavorable wind direction, $P[L]$ is the probability of leg member failure, and $P[C / L W]$ is the probability of collapse under the occurrence of both most unfavorable wind direction and leg member failure.
The collapse probability $P[C]$ should be limited to a certain value that is acceptable to the society. However, so far there is no specific standard value proposed by researchers or in standards. Still risk management should be adopted to 


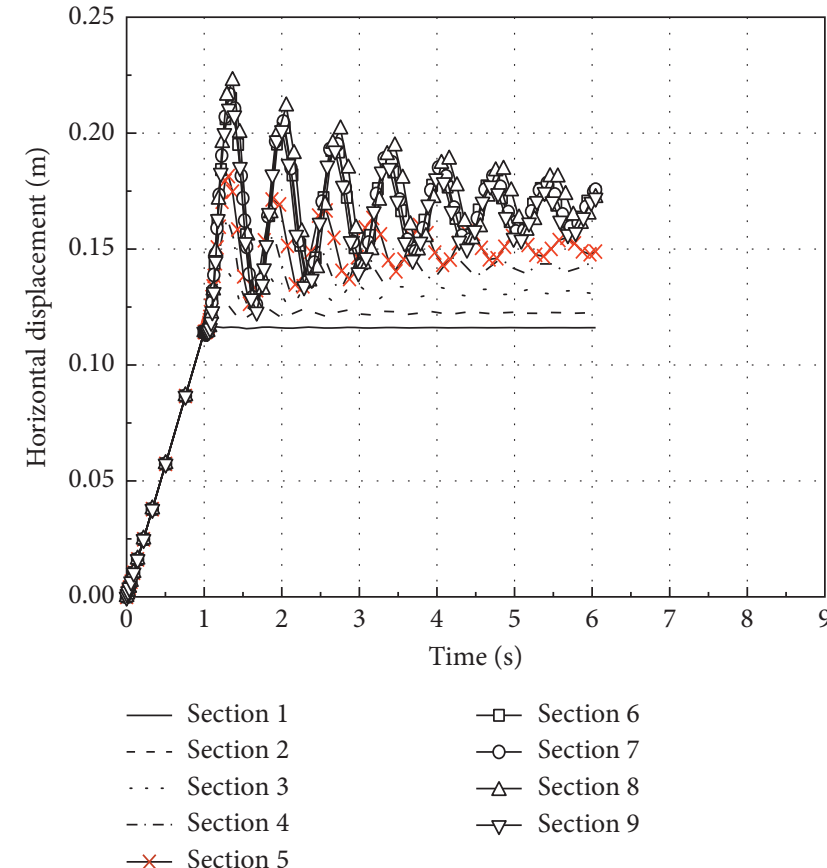

(a)

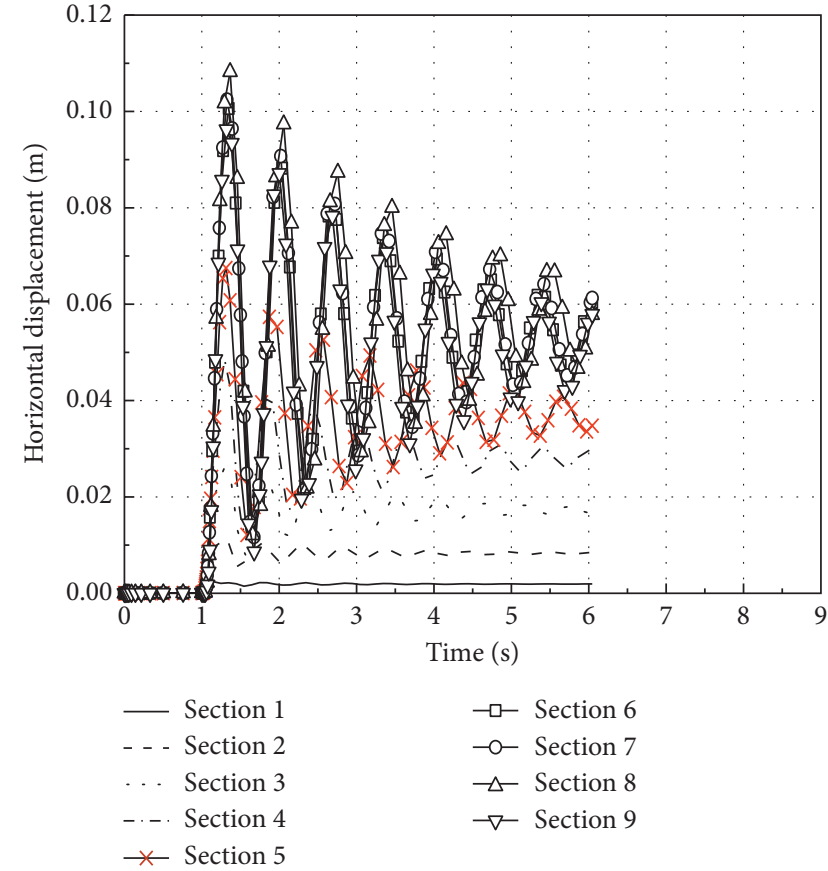

(b)

Figure 11: Leg member removal in angle-leg 2 at wind direction Ang-A. (a) Down wind direction; (b) vertical wind direction.

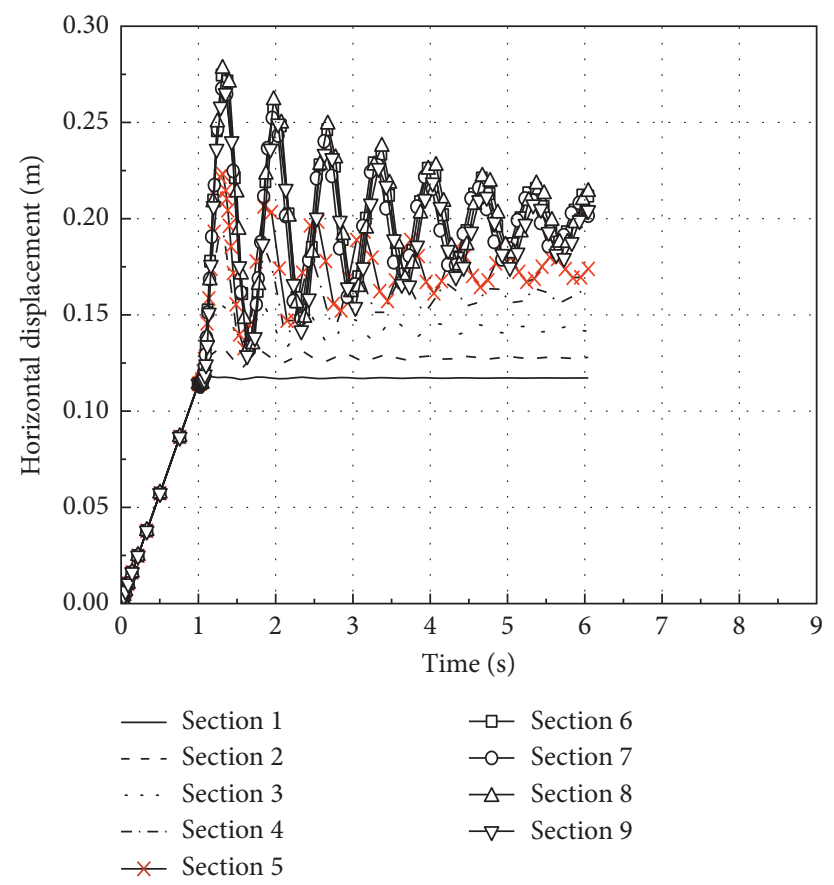

FIgURE 12: Leg member removal in angle-leg 1 at wind direction Ang-B.

minimize the probability of the three terms in (6). To this end, three different levels of anticollapse strategies should be adopted in the design and renewal of latticed telecommunication towers: (a) to avoid the most unfavorable wind direction through proper design; (b) to protect or enhance the critical leg member that has potential to trigger a collapse; and (c) to prevent tower collapse through anticollapse design, such as alternative load path or bridge over method.

Note that $P[W]$ and $P[L]$ actually are two irrelevant variables. $P[W]$ could be predicted by the statistics of 


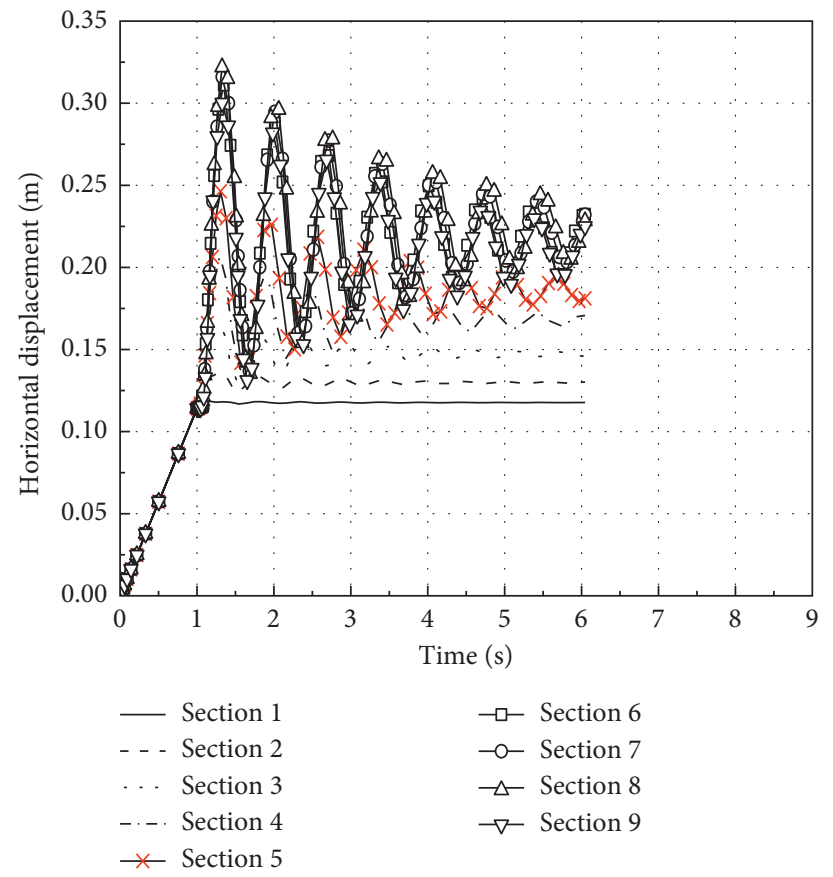

FIgURE 13: Leg member removal in angle-leg 3 at wind direction Ang-B.

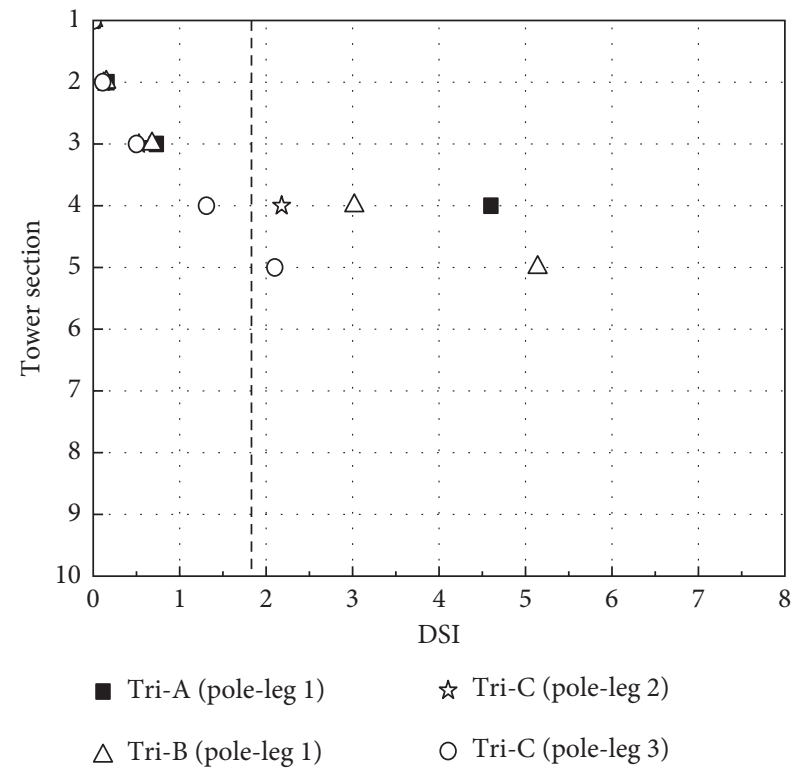

(a)

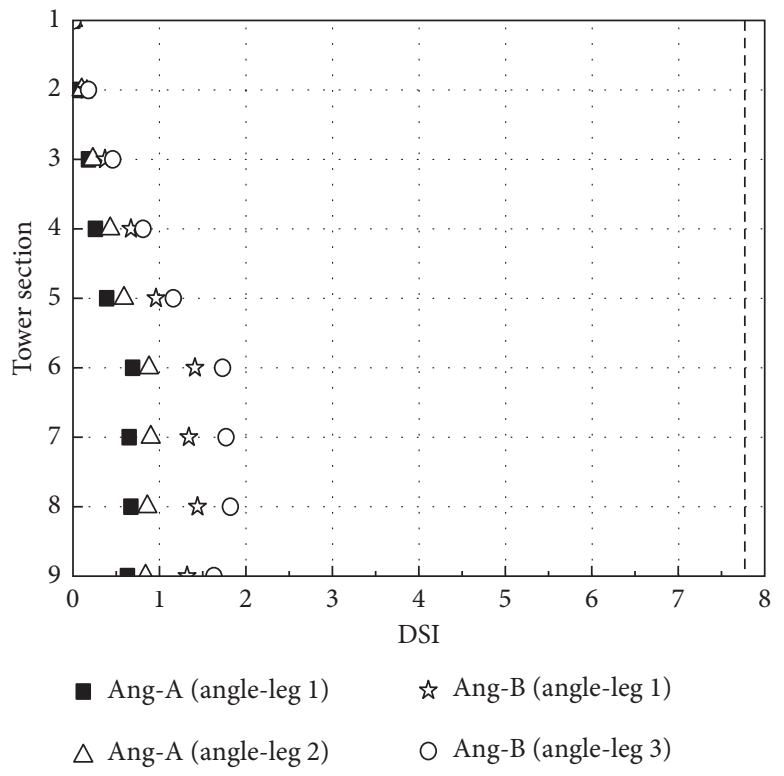

(b)

Figure 14: DSI of the towers. (a) Tripole tower; (b) angle tower.

local prevailing wind range and wind rose diagram. $P[L]$ is hard to be predicted, for the leg member failure may be caused by vandalism, rather than wind load. According to GSA and DoD, the members in lower elevation are more vulnerable than those in higher elevation. Therefore, a relative value of $P[L]$ based on member elevation could be used in the assessment of $P[C]$, as shown in Figure 15.
In alternative load path method, the aim is to control the probability $P[C / L W]$, which is to minimize the propagation of initial failure. The probability $P[C / L W]$ could be calculated as

$$
P\left[\frac{C}{L W}\right]=\frac{n_{c}}{n},
$$

where $n_{c}$ and $n$ stand for the number of the collapse scenarios and that of all the failure scenarios, respectively. 


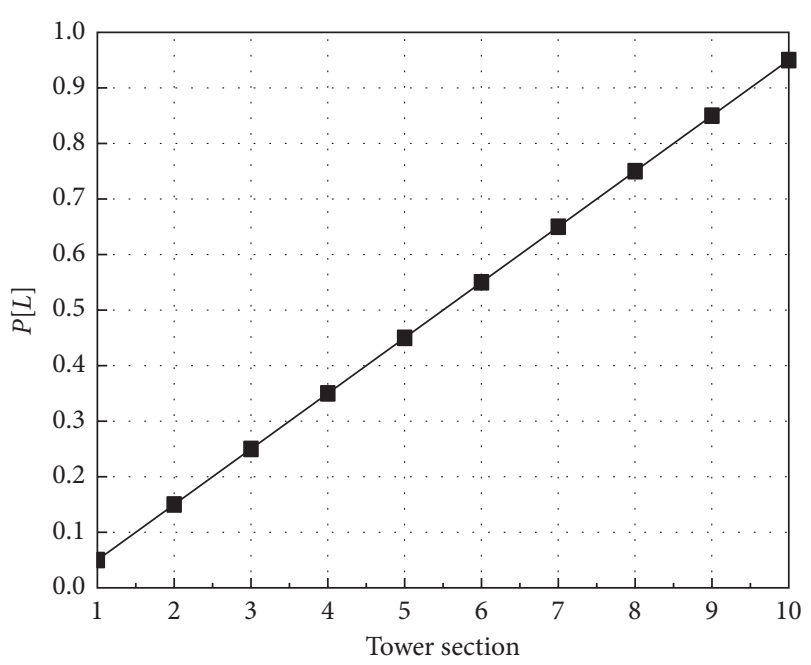

Figure 15: Probability of leg member failure.

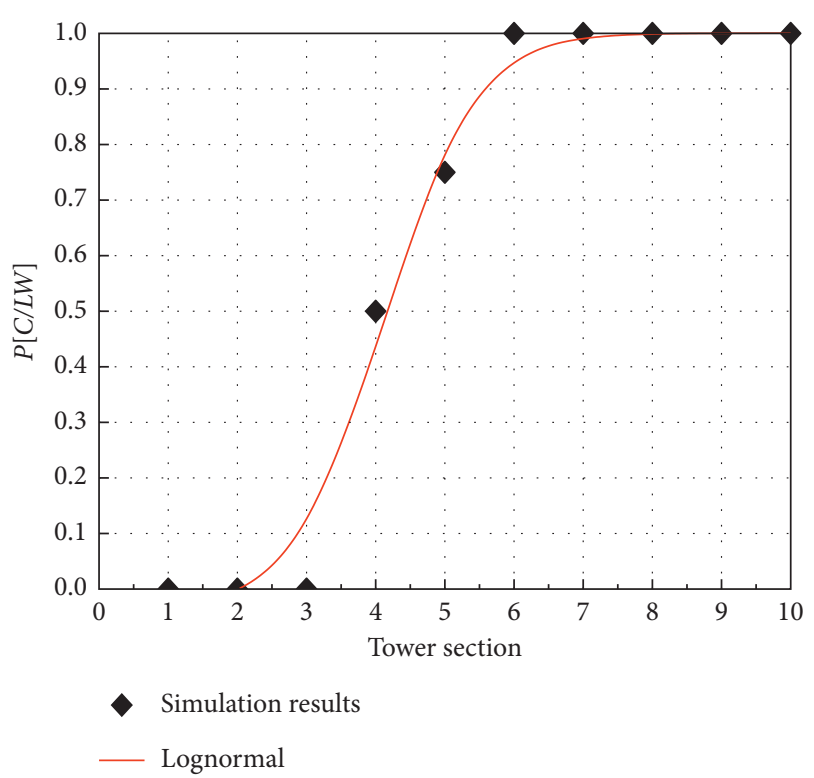

Figure 16: $P[C / L W]$ of tripole tower under design wind load referring to elevation.

Based on the aforementioned analysis, the probability $P[C / L W]$ of tripole tower under design wind load referring to elevation which is calculated by (7) is illustrated in Figure 16. Lognormal distribution function [20] is adopted to fit the probability $P[C / L W]$ of tripole tower under design wind load referring to elevation. As shown in Figure 16, the collapse probability of tripole tower under the occurrence of both most unfavorable wind direction and leg member failure follows a lognormal distribution. More study in the future should be focused on the probability $P[C / L W]$ of various types of tripole tower.

If all representative unfavorable wind directions and member failure scenarios are taken into account in the analysis, it can be assumed that $P[W] P[L]=1$ and that only the conditional probability $P[C / L W]$, namely, the collapse probability under certain level of wind load after initial failure, is adopted

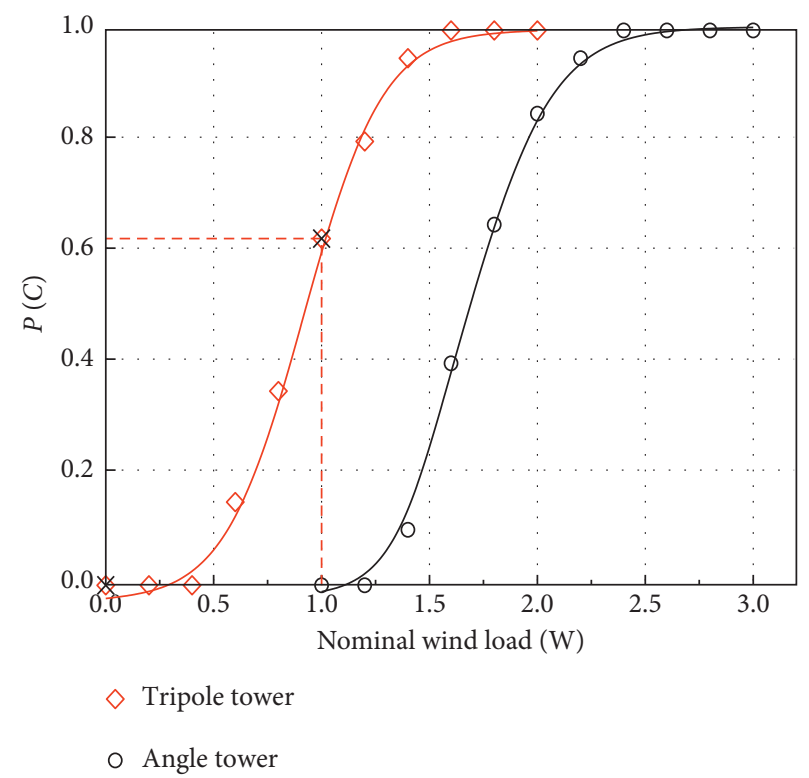

FIgURE 17: Progressive collapse fragile curves of the towers.

to assess the potential to progressive collapse of latticed towers. Therefore, the collapse probability $P[C]$ of $50 \mathrm{~m}$ high tripole tower under design wind load can be calculated as

$$
P[C]=\frac{n_{c}}{n}=0.625 \text {. }
$$

The collapse probability of $50 \mathrm{~m}$ high angle tower under design wind load is zero which means the robustness of this tower is enough to resist progressive collapse under design wind load.

In order to assess the collapse probability of the latticed towers under different normalized wind loads, 10 nominal wind levels are applied at $50 \mathrm{~m}$ high tripole tower and $50 \mathrm{~m}$ high angle tower. Aforementioned design wind load is defined as $1.0 \mathrm{~W}$. The progressive collapse fragile curves of the towers could be established as shown in Figure 17, which can also be described by the lognormal distribution function. The vertical axis in Figure 17 is the collapse probability in (6), whilst the horizontal axis is the nominal wind load, namely, intensity measure (IM).

When $\mathrm{IM}=1.0 \mathrm{~W}$ ( $\mathrm{W}$ is the design wind load), the corresponding value is the collapse probability under design wind load, which is 0.625 for tripole tower and zero for angle tower. It suggests that angle tower completely meets the anticollapse demand, even though anticollapse design is normally not considered in the design of the tower. The collapse probability of robust latticed tower is supposed to be zero in any scenarios of expected member failure under design wind load $(P[C]=0$ when $\mathrm{IM} \leqq 1.0 \mathrm{~W})$.

In the anticollapse design of latticed tower, progressive collapse fragile curve should be used to assess the anticollapse performance of the tower as follows:

(1) Establish a numerical model of the overall latticed tower, chose one or several unfavorable wind direction, and conduct a dynamic analysis of member removal 


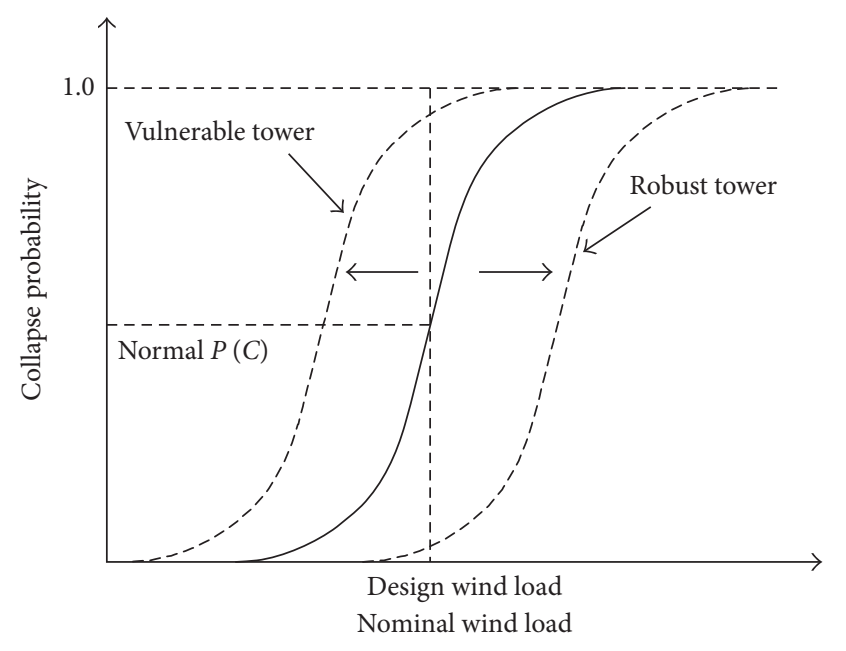

FIgURE 18: Anticollapse design.

(2) Repeat step 1 for all representative removal scenarios under certain nominal wind load and calculate the collapse probability

(3) Continuously change the nominal wind load and repeat step 1-2 to obtain a series of collapse probability under nominal wind load, and plot the progressive collapse fragile curve

(4) Considering the construction cost and safety of the tower, decide the acceptable collapse probability of the tower under certain wind load level

(5) Change the design of the tower and repeat step 1-4 to obtain an acceptable progressive collapse fragile curve (more vulnerable but cheaper cost or more robust but expensive cost) as shown in Figure 18

As shown in Figure 18, various progressive collapse fragile curves are obtained by changing the design of the tower. Normal $P[C]$ corresponds to design wind load on the tower. By enhancing the tower, the curve would shift toward right which means the collapse probability decreases under each level of wind loads. On the contrary, the curve would shift toward left by weakening the tower, which means the collapse probability increases under each level of wind loads, but the construction cost of tower would decrease.

\section{Conclusions}

In this paper, nonlinear dynamic analysis is conducted on typical standard latticed telecommunication tripole tower and angle tower by alternative load path method. The finite element models for two towers subjected to design wind loads are developed by ABAQUS. The following conclusions are made:

(1) For $50 \mathrm{~m}$ high standard tripole tower, the member failure in the first three tower sections from tower top would not trigger the collapse of the tower. From the fourth tower section to tower bottom, the member failure at certain wind direction may cause a collapse. Wind direction Tri-A that causes single pole-leg in compression is the most unfavorable wind direction for tripole tower.

(2) For $50 \mathrm{~m}$ high standard angle tower, the single member failure in any tower section would not cause the collapse of the tower. Wind direction Ang-B is the most unfavorable wind direction for angle tower.

(3) A progressive collapse fragile curve based on collapse probability of telecommunication tower under wind loads is proposed to assess the anticollapse performance of the towers.

\section{Conflicts of Interest}

The authors declare that there are no conflicts of interest.

\section{Acknowledgments}

The project is supported by National Natural Science Foundation of China (No. 51408106), China Postdoctoral Science Foundation (2017M622965), Chongqing Postdoctoral Special Foundation (Xm2017095), Scientific Research Program Funded by Shaanxi Provincial Education Department (17JK1154), and Xijing University Special Foundation (XJ17T07), which are gratefully acknowledged.

\section{References}

[1] American Society of Civil Engineers, ASCE 7-05: Minimum Design Loads for Buildings and Other Structures, ASCE, New York, NY, USA, 2005.

[2] Department of Defense (DoD), Unified Facilities Criteria (UFC): Design of Structures to Resist Progressive Collapse, DoD, Washington, DC, USA, 2013.

[3] United States General Services Administration (GSA), Progressive Collapse Analysis and Design Guidelines for New Federal Office Buildings and Major Modernization Projects, GSA, Washington, DC, USA, 2003.

[4] Telecommunication Industry Association (TIA), Structural Standard for Antenna Supporting Structures and Antennas, TIA, Arlington, TX, USA, 2005.

[5] Canadian Standard Association (CSA), Antennas, Towers and Antenna Supporting Structures, CSA, Mississauga, Ontario, Canada, 2006.

[6] G. Powell, "Progressive collapse: case study using nonlinear analysis," in Proceedings of the Structures Congress and Exposition, pp. 2185-2198, New York, NY, USA, 2005.

[7] P. Ruth, K. A. Marchand, and E. B. Williamson, "Static equivalency in progressive collapse alternative path analysis: reducing conservatism while retaining structural integrity," Journal of Performance of Constructed Facilities, vol. 20, no. 4, pp. 349-364, 2006.

[8] J. Kim and T. Kim, "Assessment of progressive collapseresisting capacity of steel moment frames," Journal of Constructional Steel Research, vol. 65, no. 1, pp. 169-179, 2009.

[9] F. Fu, "Progressive collapse analysis of high-rise building with 3-D finite element modeling method," Journal of Constructional Steel Research, vol. 65, no. 6, pp. 699-708, 2009.

[10] K. Khandelwal and S. El-Tawil, "Pushdown resistance as a measure of robustness in progressive collapse analysis," Engineering Structures, vol. 33, no. 9, pp. 2653-2661, 2011. 
[11] B. I. Song, K. A. Giriunas, and H Sezen, "Progressive collapse testing and analysis of a steel frame building," Journal of Constructional Steel Research, vol. 94, pp. 76-83, 2014.

[12] Y. El Kamari, W. Raphael, and A. Chateauneuf, "Reliability study and simulation of the progressive collapse of Roissy Charles de Gaulle Airport," Case Studies in Engineering Failure Analysis, vol. 3, pp. 88-95, 2015.

[13] S. Gerasimidis and J. Sideri, "A new partial-distributed damage method for progressive collapse analysis of steel frames," Journal of Constructional Steel Research, vol. 119, pp. 233-245, 2016.

[14] B. Asgarian, S. D. Eslamlou, A. E. Zaghi, and M. Mehr, "Progressive collapse analysis of power transmission towers," Journal of Constructional Steel Research, vol. 123, pp. 31-40, 2016.

[15] ABAQUS Theory Manual, Version 10.0.1 Hibbitt, Karlsson and Sorensen, Inc., Pawtucket, RI, USA, 2003.

[16] China Tower Company, Drawing Collection of Telecommunication Steel Tower, China Tower Company, Beijing, China, 2014.

[17] GB50009-2012, Load Code for the Design of Building Structures, China Architecture \& Building Press, Beijing, China, 2012.

[18] GB50135-2006, Code for Design of High-Rising Dtructures, China Architecture \& Building Press, Beijing, China, 2006.

[19] B. R. Ellingwood and D. O. Dusenberry, "Building design for abnormal loads and progressive collapse," Computer-Aided Civil and Infrastructure Engineering, vol. 20, no. 3, pp. 194205, 2005.

[20] Y. Li, X. Z. Lu, H. Guan, P. Ren, and L. Qian, "Probabilitybased progressive collapse-resistant assessment for reinforced concrete frame structures," Advances in Structural Engineering, vol. 19, no. 11, pp. 1723-1735, 2016. 


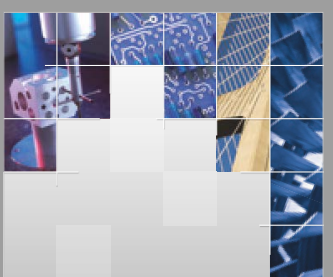

\section{Enfincering}
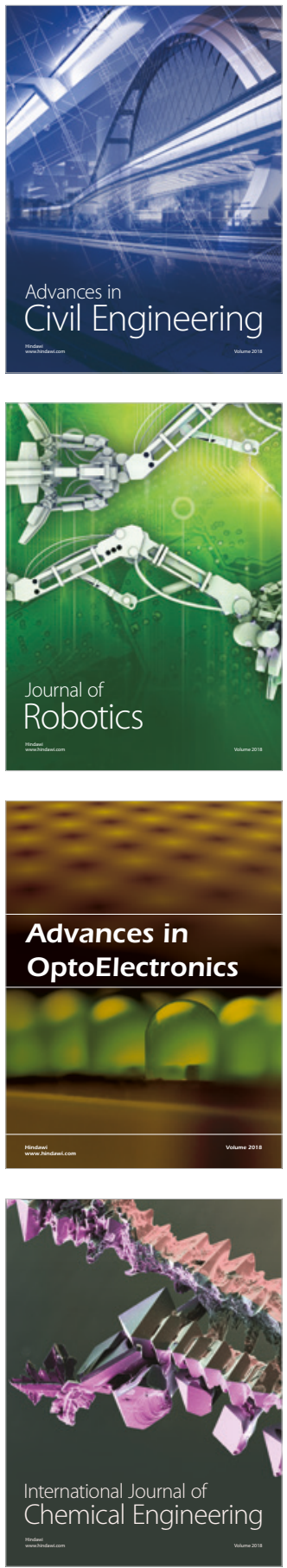

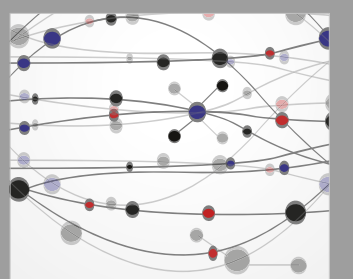

\section{Rotating \\ Machinery}

The Scientific World Journal

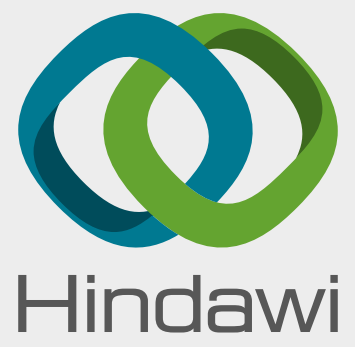

Submit your manuscripts at

www.hindawi.com
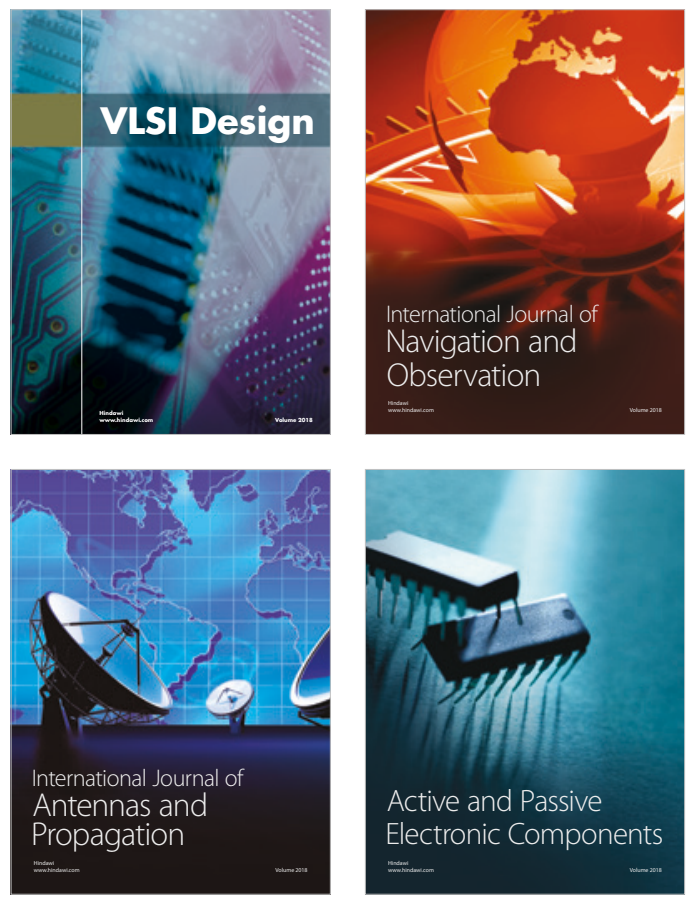
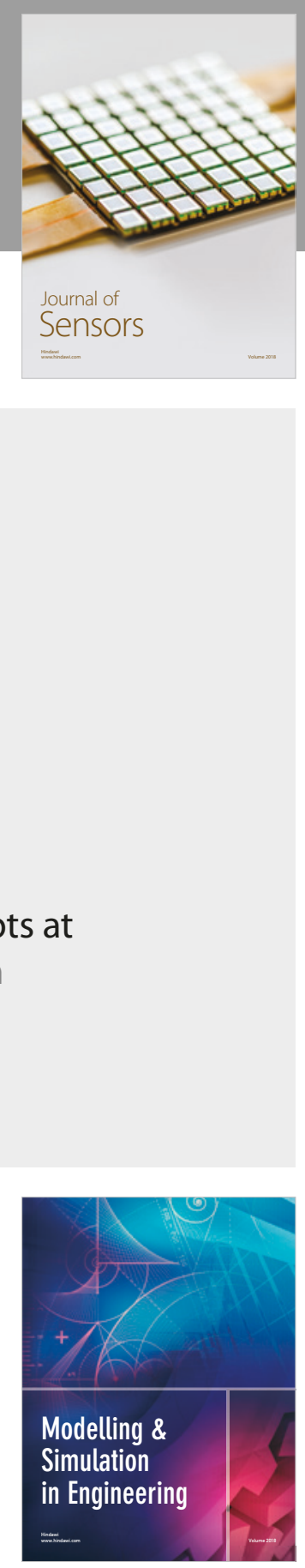

\section{Advances \\ Multimedia}
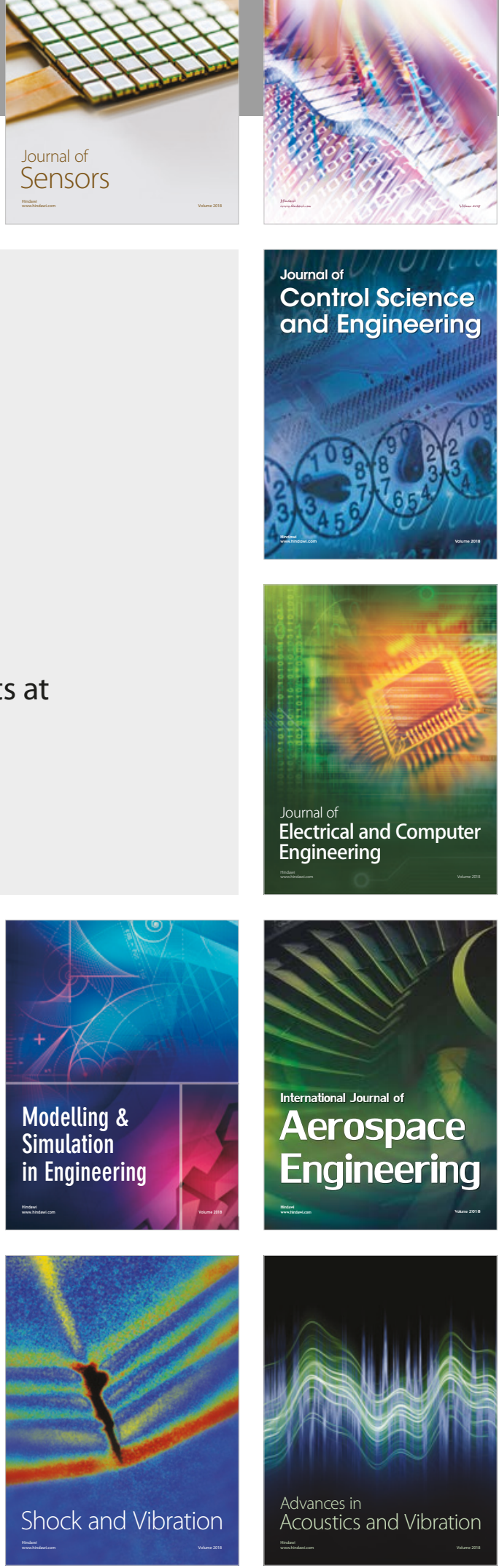